\title{
Flow Bifurcation at a Longitudinal Training Dam: Effects on Local Morphology
}

\author{
Timo de Ruijsscher ${ }^{1, *}$, Suleyman Naqshband ${ }^{1}$, and Ton Hoitink ${ }^{1, * *}$ \\ ${ }^{1}$ Wageningen University, Department of Environmental Sciences, Hydrology and Quantitative Water \\ Management Group, P.O. Box 47, 6700 AA, Wageningen, the Netherlands
}

\begin{abstract}
Longitudinal training dams (LTDs) have been built over a length of $10 \mathrm{~km}$ in the Dutch River Waal as an alternative to groyne fields, splitting the river in a fairway and a bank-connected side channel in the inner bend. Here, we study the physical mechanisms governing the three-dimensional flow and its effect on local morphology at the flow divide using a mobile bed physical model of an LTD, centred around a side channel intake. In line with previous experiments, polystyrene granules are used as a lightweight sediment that allows to achieve dynamic similarity between the model and the prototype. An Acoustic Doppler Velocimetry (ADV) profiler is used to monitor the flow characteristics, whereas a line laser scanner set-up is used to measure the morphological imprint of the flow near the bifurcation point. To study the dependence of the results on the sill height at the side channel intake, different forms and heights of the sill are used. First results show striking similarities with measurements from the field pilot in the Waal River, as well as larger sedimentation in the side channel for a uniform low sill compared to a downstream increasing sill height.
\end{abstract}

\section{Introduction}

Longitudinal training dams (LTDs) have been built over a length of $10 \mathrm{~km}$ in the inner bend of the Waal River near the city of Tiel, the Netherlands (see Figure 1). LTDs serve multiple purposes in which they replace the traditional groynes, of which the most important [1]

- to restrict the river width (and therefore increase the water depth in the fairway) at low discharges,

- to increase discharge capacity at high discharges (and therefore reduce flood risk),

- to minimize bed degradation, and

- to create ecologically favourable conditions in the side channel compared to the former groyne fields [2].

The LTDs in the Waal River have a design height to be submerged about 100 days per year. They are constructed with a sill at the upstream entrance of the side channel and an unobstructed outflow at the downstream side. Additionally, multiple so-called openings are

\footnotetext{
*e-mail: timo.deruijsscher@wur.nl

**e-mail: ton.hoitink@wur.nl
} 


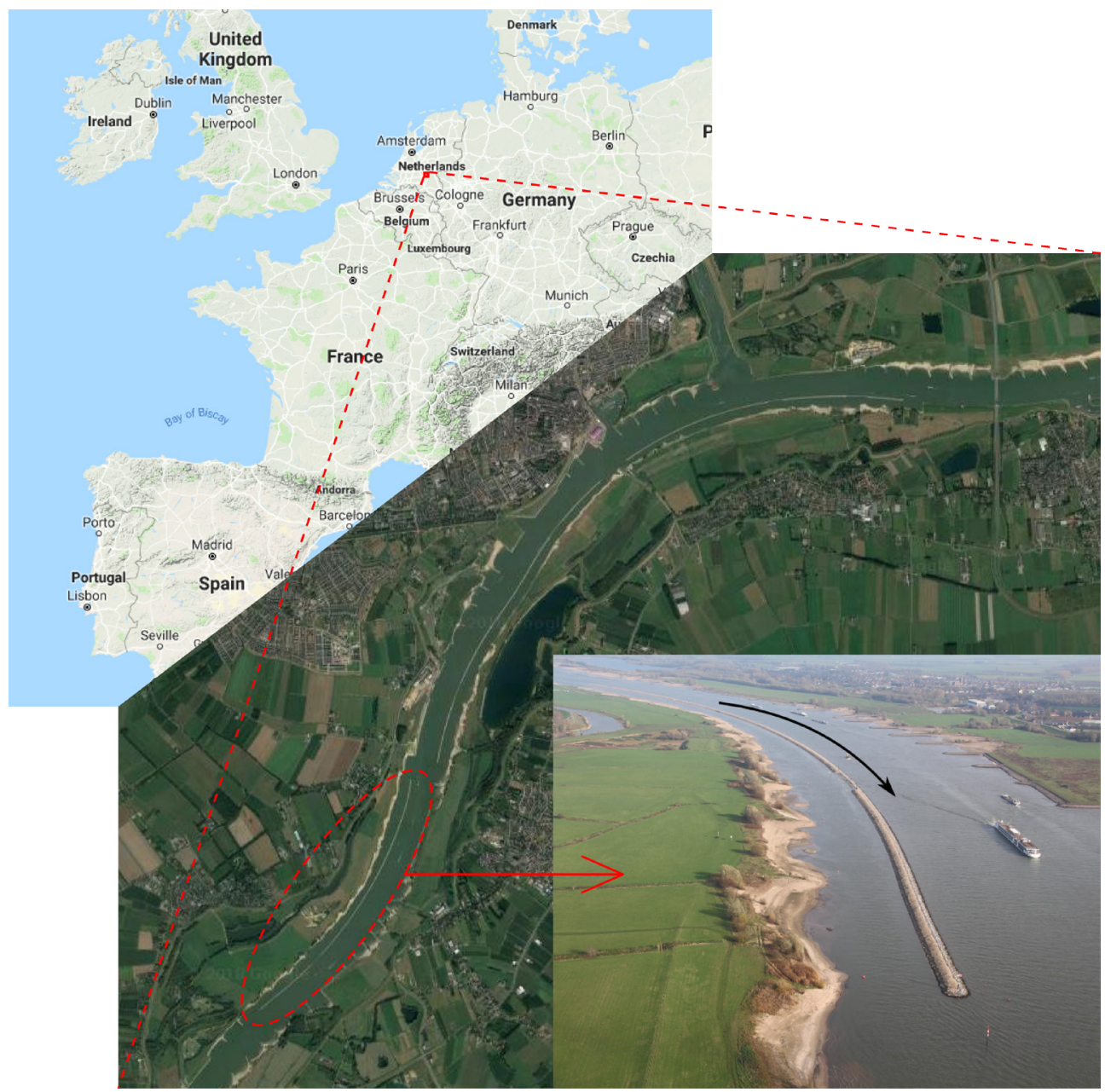

Figure 1. An overview of the LTD section in the Dutch Waal River showing the location in the Netherlands, a satellite image of the river section with LTDs (courtesy: Google) and an aerial photograph of the most downstream LTD (courtesy: Rijkswaterstaat).

present (stretches of the LTD with lowered crest) through which interaction of fairway and side channel in terms of water and sediment is facilitated.

Despite the fact that different kinds of LTD-like structures can be found in multiple rivers internationally (e.g. the Loire River near Chatillon sur Loire in France and the Main River near Karlstadt am Main in Germany), there is not yet in-depth knowledge on the way they regulate water and sediment flows. Recent work of Le et al. [3] indicates that the sediment availability at the side channel intake is crucial for the two-channel stability. In the present pilot study, this is tackled by constructing a sill at the side channel entrance, thus being able to regulate the bed load sediment flux into the side channel [1].

Erosion and deposition patterns in both fairway and side channel are important for river managers, as they might increase the need for dredging the fairway or limit the suitability of the side channel to be used by recreational boaters. Beside this practical interest in the applicability of LTDs there is also a more general interest, because the entrance of an LTD side 
channel may be seen as a specific case of a flow divide, with a sill located at the divide. The situation also bears some similarity to the classical situation of flow and bed load transport over an oblique weir.

Here, we study the physical mechanisms governing the three-dimensional flow and its effect on local morphology at this specific type of flow divide, to be able to predict hydroand morphodynamic effects after future construction of LTDs more accurately. This is done by using measurements from a physical scale model in a flume, as well as high-resolution bed level data from the pilot case in the Waal River. We are particularly interested in the local effect of the sill geometry at the side channel intake on both the flow and the resulting morphological patterns.

\section{Methods}

In the current study, the flow divide at the entrance of an LTD side channel is studied using a scale model with movable bed. Both bed level and flow velocities are monitored. Four designs of the sill are studied. The resulting bed level data are compared with an extensive morphological field data set.

\subsection{Physical scale model}

In the Kraijenhoff van de Leur Laboratory for Water and Sediment Dynamics at Wageningen University \& Research (the Netherlands), a flume with a physical scale model of an LTD is used. The flume has an inner width of $2.6 \mathrm{~m}$ and a length of the measurement reach of $12.0 \mathrm{~m}$. The physical model is scaled from the prototype (the side channel inflow of the most downstream LTD in the Waal River, see aerial photograph in Figure 1) with a factor 60 in all spatial dimensions. A view from downstream on the model with flowing water is offered in Figure 2. To assure dynamic similarity, lightweight particles (polystyrene granules) are used as surrogate sediment, with density $\rho_{\mathrm{s}}=1055 \mathrm{~kg} / \mathrm{m}^{3}$ and size $D_{50}=2.1 \mathrm{~mm}$ and $D_{90}=2.9 \mathrm{~mm}$. For details on this method, see Vermeulen et al. [4].

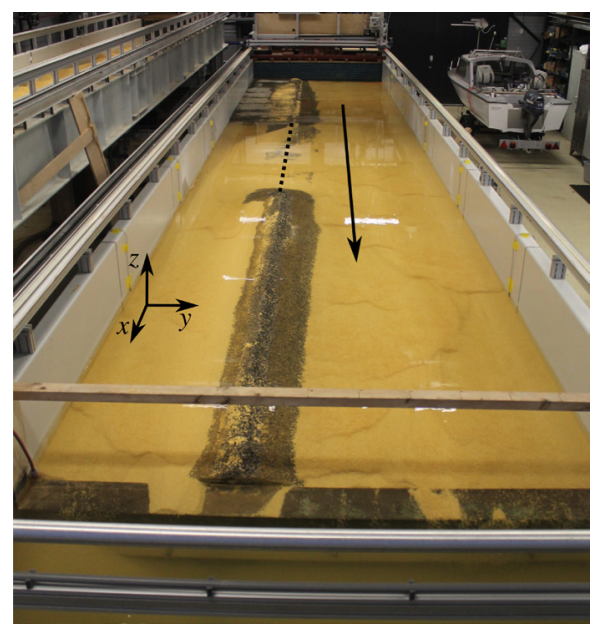

Figure 2. Scale model of the LTD with flowing water. The arrow denotes the flow direction in the fairway and the dashed line indicates the location of the sill. 
To study the effect of sill geometry at the side channel intake on the flow and the morphological patterns, four sill geometries are specified. These are illustrated in Figure 3, showing from left to right A) uniform low, B) downstream increasing, C) downstream decreasing, and D) uniform high sill height. These specific geometries are chosen, in order to represent a large (A) and a small (d) total cross-sectional inflow area, and a cross-sectional inflow area that is larger upstream than downstream (B) and vice versa (C). This way both amount and longitudinal location of sediment transport might be steered. To distinguish the effect of different phases of the hydrograph, two typical hydrological conditions for the field pilot are used, resulting in an emerged and a submerged LTD crest: top and bottom row in Figure 3, respectively. For each sill configuration, the experiment with emerged LTD crest (low water level) is directly followed by the one with submerged LTD crest (high water level), without levelling the bed.
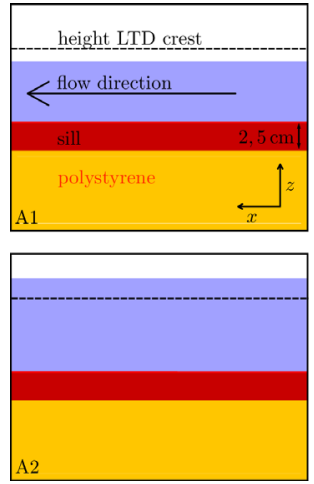
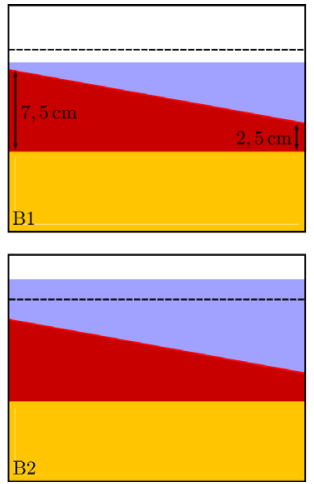
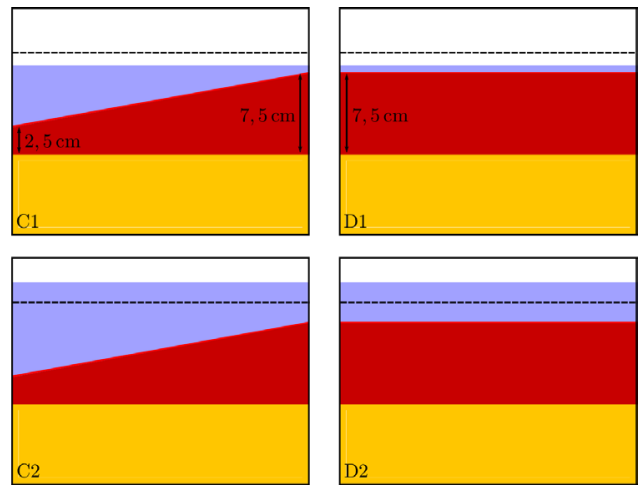

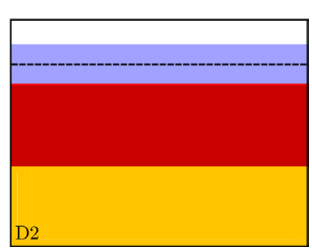

Figure 3. Side view of the eight cases studied with the physical scale model. The top row indicates a situation with an emerged LTD crest and the bottom row indicates a submerged LTD crest. The four studied sill geometries are: A) uniform low, B) downstream increasing, C) downstream decreasing, and D) uniform high sill height. As a reference, the LTD crest height (dashed line) and the flow direction in the fairway (arrow) are indicated.

\subsubsection{Flow velocity measurements}

Flow velocity is measured using a Vectrino Profiler, which is a profiling acoustic velocimeter, measuring flow magnitude and direction in vertical bins of $1 \mathrm{~mm}$ over a total vertical range of $3 \mathrm{~cm}$ and at a frequency of $50 \mathrm{~Hz}$. Besides, a point measurement of the bed level directly underneath the instrument is taken. The data gathered are used to quantify the flow patterns around the intake of the LTD side channel, and to estimate the discharge division over the two channels. For the latter, also water level is monitored continuously during the experiment at eight points along the side walls of the flume.

\subsubsection{Bed level measurements}

The bed topography is measured continuously during different phases of the experiment, being the initial dry-bed condition, the initial still water condition and the situation after development of dunes. For this purpose, a line laser scanner is used. The use of a line laser scanner for bed level measurements is a new measurement method, in which the bed elevation 
is detected from reflection of light projected on the bed making use of a line laser and a 3Dcamera, as illustrated in Figure 4. This way, the bed level can be measured without disturbing the flow [5]. The bed is scanned with an along-flow resolution of $2 \mathrm{~mm}$ and an average cross-flow resolution of approximately $3 \mathrm{~mm}$, in eight parallel partly-overlapping swipes.

Beside the measurements with the line laser scanner, the Vectrino Profiler is used to gather bed level elevation directly underneath the instrument. These data are used to quantify dune characteristics during the start-up phase of the experiment and to estimate the division of sediment transported as bedload over the two channels.

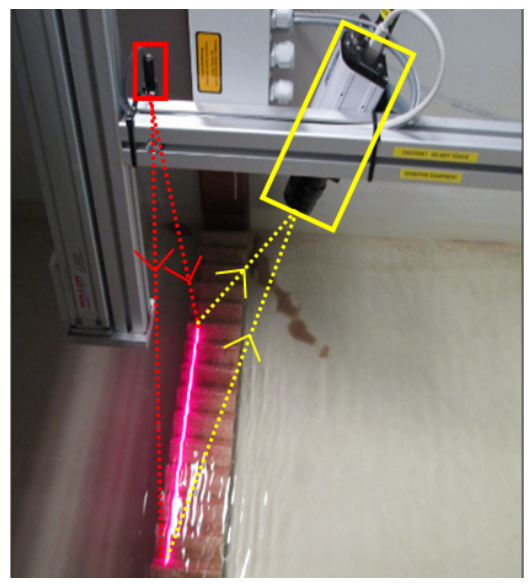

Figure 4. Picture of the line laser scanner measuring a sawtooth profile on the bottom of a flume, showing the line laser (red) and the 3D-camera (yellow). The red light on the profile is the line emitted by the laser. The travel path of the emitted and reflected laser light is illustrated by red and yellow dashed lines, respectively.

\subsection{Morphological field survey}

In-situ measurements of the bed topography in the field pilot in the Waal River are carried out making use of MultiBeam EchoSoundings (MBES). MBES is an acoustic method using a submerged array of sonar beams, receiving sound wave reflections from the bed with a detectable range that can be used to determine the bed profile. Such high resolution measurements are carried out biweekly for the fairway of the river and bimonthly for the whole river, including side channels. These data are used to validate the findings in the scale model.

\section{Results}

MBES measurements at different phases of the hydrograph are compared, as can be seen in Figure 5. One can see the pattern of an erosion pit at the side channel entrance, followed by a downstream region of sedimentation. This is worth studying not only for the scientific question of sediment transport over an oblique weir, but also from a river management perspective. Sedimentation in the side channel limits its suitability for recreational boating.

This pattern is reproduced in the scale model, as shown in Figure 6, showing a scan of the scale model with still water. Comparing the morphological pattern in the scale model with the MBES results, both cases show a striking similarity at the side channel side of the LTD 


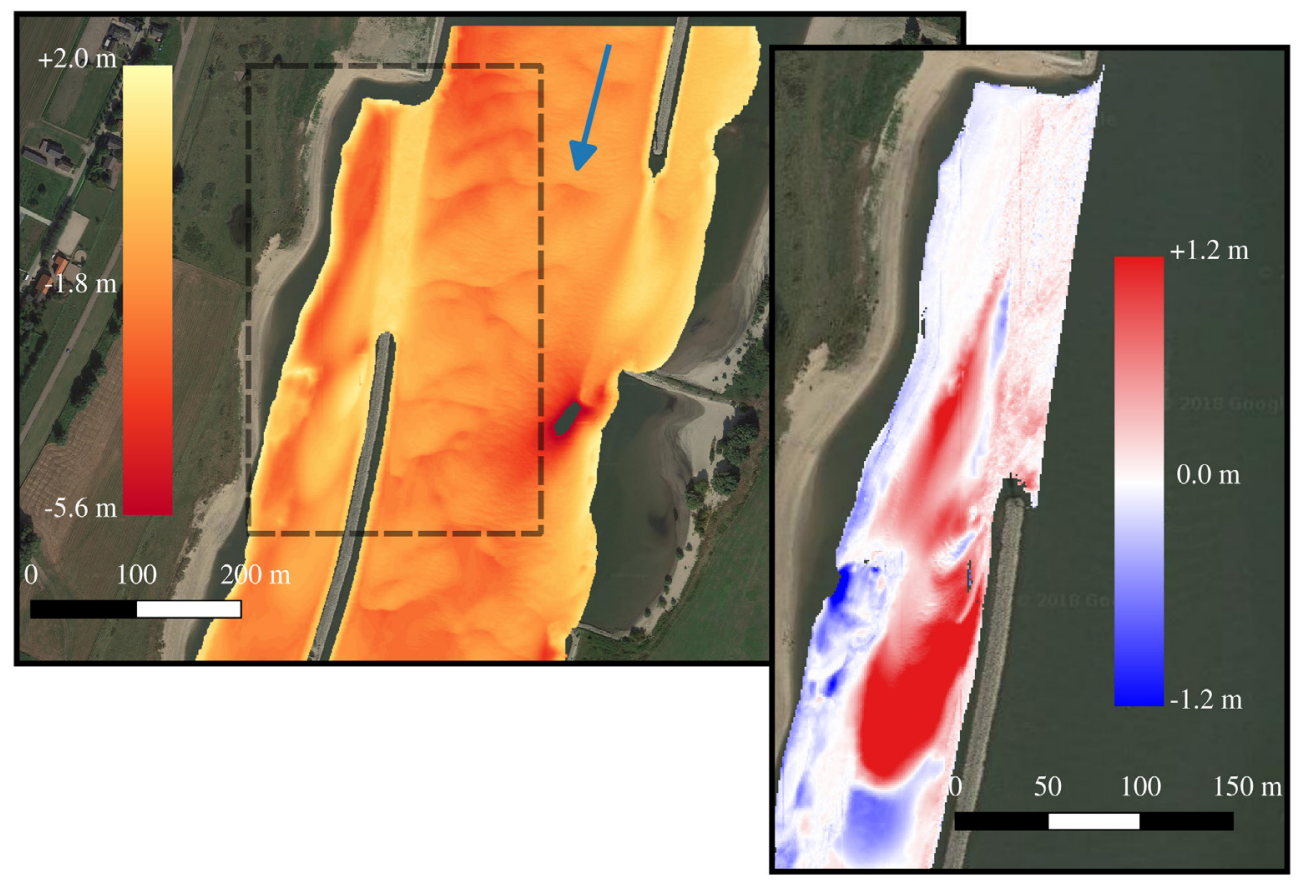

Figure 5. MBES measurements of the bed in the Waal at the entrance of an LTD side channel. The arrow indicates the flow direction in the fairway. Left: bed level in metres above NAP in June 2017. Right: difference in bed level between June and February 2017, where red indicates sedimentation.

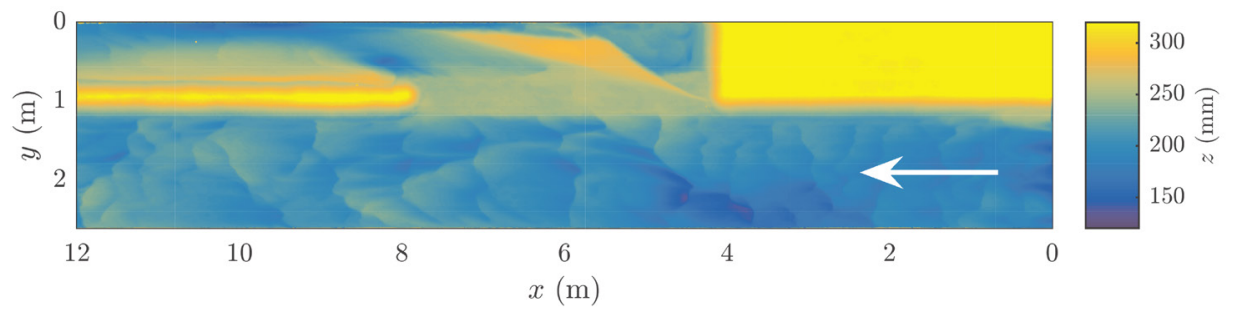

Figure 6. Top view of the LTD scale model making use of a line laser scanner at the end of experiment A1 (i.e., a low sill of uniform height with emerged LTD crest). The arrow denotes the flow direction.

head. The large erosion close to the flume wall in the side channel $(y=0 \mathrm{~m})$ might be a wall effect which is not representative for the prototype in the actual river.

Only part of the proposed experimental cases have been studied for the time being, i.e. A1, A2, B1 and B2. Figure 7 shows the bed level difference compared with the initial situation. It is clear that at the upstream part of the side channel, more sedimentation occurs with a uniform low sill (A1/A2), compared to a downstream increasing sill (B1/B2). However, downstream of the sill this effect is negligible or even reversed. The difference in the amount of sedimentation in the side channel might be caused by the on average lower sill height in case A, causing particles to be transported more easily via bed load transport over the sill. Possible differences in discharge distribution (and hence velocity in the side channel) 
over the two channels might also play a role. This should be investigated further. For both sill geometries, it is clear that regions of sedimentation become eroded again when the high water sets in.
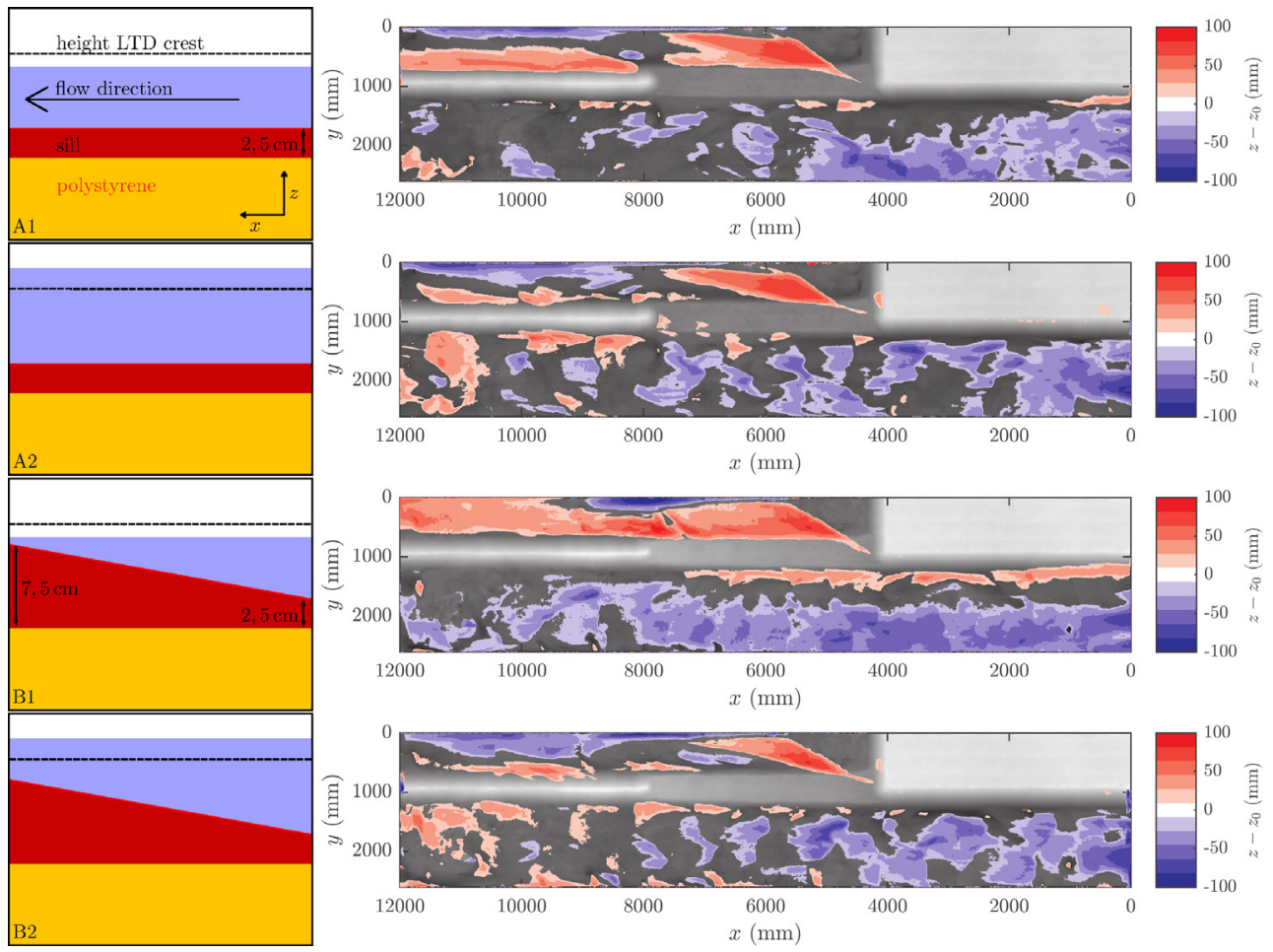

Figure 7. Difference plots for bed level height between the initial bed level and the end of the experiment. Red indicates sedimentation and blue indicates erosion. The background shows the initial bed elevation in gray. On the left hand side, the sill geometry and water level are schematically represented.

\section{Conclusions}

Experiments are performed studying the effect of sill geometry at the entrance of an LTD side channel, using a physical scale model with movable bed. Bed level patterns around the sill in the scale model show striking similarities with the patterns observed in the field pilot in the Waal River, giving confidence in the reliability of the scale model. From the first experiments, it can be concluded that at the most upstream part of the side channel, more sedimentation occurs for a uniform low sill height than for a downstream increasing sill height, although this effect is negligible or even reversed downstream of the sill. In general, regions of large sedimentation become eroded again when the conditions with high discharge and water level are set.

\section{Outlook}

Of the four different sill geometries (see Figure 3), experiments with downstream decreasing (C) and uniform high sill height (D) still have to be performed, both with emerged and 
submerged LTD crest. However, the morphological patterns from the first two experiments look promising. Clear differences in morphological patterns are observed between the experiments. To get a better understanding of the mechanisms playing a role in the sediment distribution over the two channels and the role of the sill geometry therein, flow velocity patterns (both horizontally and vertically) as well as the discharge division over the two channels will also be analysed.

A first comparison between the bed level in the physical scale model and the field pilot in the Waal River looks promising. However, a more in-depth comparison should be performed in order to be able to translate the mechanisms observed in the scale model to the field pilot. Special attention will also be paid to the comparison of bed form characteristics-which determine the bed roughness- between field pilot and flume. The combined dataset will be used to get a better understanding on flow and bed load sediment transport over oblique weirs and on tuning morphological stability of a two-channel LTD system in general.

This research is part of the research programme RiverCare, supported by the Dutch Technology Foundation STW, which is part of the Netherlands Organization for Scientific Research (NWO), and which is partly funded by the Ministry of Economic Affairs under grant number P12-14 (Perspective Programme).

\section{References}

[1] Rijkswaterstaat Oost-Nederland, H. Eerden, E. van Riel, R. de Koning, E. Zemlak, N. Aziz, Tech. rep., Rijkswaterstaat Oost-Nederland (2011)

[2] F.P.L. Collas, A.D. Buijse, L. van den Heuvel, N. van Kessel, M.M. Schoor, H. Eerden, R.S.E.W. Leuven, Sci. Total Environ. 619-620, 1183 (2018)

[3] T.B. Le, A. Crosato, E. Mosselman, W.S.J. Uijttewaal, Adv. Water Resour. (2018)

[4] B. Vermeulen, M.P. Boersema, A.J.F. Hoitink, J. Sieben, C.J. Sloff, M. van der Wal, J. Hydro-environ. Res. 8, 88 (2014)

[5] T.V. de Ruijsscher, A.J.F. Hoitink, S. Dinnissen, B. Vermeulen, P. Hazenberg, Water Resour. Res. 54, 2078 (2018) 